\title{
Funciones narrativas e ideológicas de los personajes de inmigrantes y de sus descendientes en la narrativa española
}

\author{
Narrative and ideological functions of immigrant \\ and descendants of immigrant characters in Spanish narrative
}

\author{
Marcin Kołakowski \\ Uniwersytet Warszawski \\ m.kolakowski@uw.edu.pl
}

\begin{abstract}
The present paper is aimed to analyze how certain concepts of political identity are translated into poetics of identity in contemporary Spanish narrative. The analysis covers four novels published since 1998, written by Spanish authors and which achieved high rates of sales and positive critical recognition. The study was not limited to specific immigrant groups in order to reflect a variety of experiences and political positions represented in the texts. The paper is a study of the image and functions of immigrant characters in selected Spanish novels of the last three decades: Háblame, musa, de aquel varón (1998) by Dulce Chacón, Ventajas de viajar en tren (2000) by Antonio Orejudo, Cosmofobia (2007) by Lucía Etxebarria and En la orilla (2013) by Rafael Chirbes. Sociologists and psychologists indicate three main classes of negative attitudes towards immigrants (citizen insecurity, threat to cultural identity and competitiveness in obtaining resources). Within this context the article aims to determine to what extent the literary representations of immigrant characters constitute reproductions or transgressions of culturally prefabricated images of the Other and explores the different narrative and ideological functions these characters play. The paper also studies the presence of discourses that support social exclusion of immigrants and the means of subverting them.
\end{abstract}

Keywords: immigrants, Rafael Chirbes, Antonio Orejudo, Lucía Etxebarria, Dulce Chacón

Un estudio sociológico llevado a cabo sobre la imagen de los inmigrantes en dos series televisivas españolas (Galán, 2006) reveló que el ser inmigrante, por lo general, suele tener connotaciones negativas asociadas. Estos inmigrantes aparecen en los 
marcos de la ilegalidad, en tramas vinculadas al tráfico de drogas, a la prostitución y al delito y en situaciones conflictivas. Asimismo, el estudio también demostró que estos personajes hicieron acto de presencia en el $25 \%$ de los episodios, siendo este un porcentaje que parece estar muy por encima de lo que ofrece la narrativa española actual. Aunque existen ciertos estudios sobre la representación de los inmigrantes en la literatura española en general (p.ej. Cruz, 2009; Leone, 2013), solo pocas investigaciones aportan un panorama relativamente amplio de la imagen de los inmigrantes en la narrativa (p.ej. Zavko, 2009; Álvarez Blanco, 2011; Odartey Wellington, 2012). No obstante, y dado el creciente aumento del número de inmigrantes y de personas de descendencia inmigrante en España, esta clase de análisis parece necesitar más atención por parte de los investigadores, ya que es innegable el fuerte impacto que la comunidad inmigrante tiene en la estructura social, económica y política del país, además de ser también objeto de un fuerte debate político.

A este respecto, el presente artículo pretende, por una parte, examinar en qué medida la representación de los personajes de inmigrantes y/o de sus descendientes reproducen o transgreden la imagen prefabricada del paria, símbolo de la miseria y de la exclusión, de la esclavitud, de la abyección y de la degradación. Por otra, se analizarán las diferentes funciones narrativas (y su papel dentro de la trama) e ideológicas que las figuras de inmigrantes o descendientes o descendientes de inmigrantes desempeñan.. El análisis abarca cuatro novelas publicadas a partir del año 1998, de autores españoles, que alcanzaron el éxito en sus ventas y que obtuvieron el reconocimiento de la crítica y, por ende, cierto eco social.

Con la intención de abarcar una variedad de experiencias y de posturas, en el presente estudio no solo se han incluido grupos de inmigrantes de orígenes particulares. Se ha investigado la imagen de los inmigrantes y descendientes de inmigrantes y sus funciones en Háblame, musa, de aquel varón (1998) de Dulce Chacón, Ventajas de viajar en tren (2000) de Antonio Orejudo, Cosmofobia (2007) de Lucía Etxebarria y En la orilla (2013) de Rafael Chirbes. Partiendo de las aportaciones de la sociología y de la psicología, que señalan tres clases principales de prejuicios contra los inmigrantes (la inseguridad ciudadana, la amenaza para la identidad cultural y la competitividad en la obtención de recursos) (Moya y Puertas, 2008), se examinarán los discursos de exclusión que operan en el marco de la narrativa que versa sobre la inmigración. Presentaré (brevemente) algunos personajes sintomáticos que, de alguna manera, desvelan la existencia de ciertas tendencias, al menos en lo que se refiere a la representación de los inmigrantes en la narrativa española actual. Además, me serviré de las tipologías formales y sustanciales así como de las propuestas tipológicas de estructuralistas polacos a fin de revelar las funciones narrativas e ideológicas de esta clase de personajes. Según las tipologías formales de Tzvetan Todorov y Oswald Ducrot (1945, pp. 261-264), los personajes se dejan categorizar según varios factores: primero, el papel que juegan en la trama (principales, secundarios, 
incidentales); segundo, su complejidad (planos, redondos); tercero, su capacidad de transformación (estáticos, dinámicos) y cuarto, su papel en la acción (pasivos, activos). En las tipologías sustanciales, propias del formalismo y estructuralismo, me he querido valer de las aportaciones de Vladimir Propp (1971) y de su concepto de siete personajes-funciones de la trama, a saber: el agresor, el donante, el auxiliar, la princesa, el mandante, el héroe y el falso héroe. Además, me serviré de la categoría de la motivación del personaje expuesta por Janusz Sławiński, quien distingue entre los siguientes tipos de motivaciones: la social (personaje como suma de exigencias y condiciones sociales de su entorno), la biológica (personaje regido por instintos, atavismos, instinto sexual, etc.), la psicológica (los personajes se mueven por su construcción psíquica), la fantástica (con personajes motivados por fenómenos no empíricos, maravillosos) y metafísica (los personajes están determinados por fuerzas ajenas a su voluntad, como el destino, la fatalidad, etc.) (2002, p. 326).

Empezaremos el análisis con Cosmofobia de Lucía Etxebarria. Esta es una novela en la que confluyen las voces de numerosos personajes del vecindario de Lavapiés en Madrid y cuyas experiencias vitales en ocasiones se entrecruzan. De los casi ciento cuarenta personajes, aparecen en ella por lo menos diecinueve inmigrantes (el $15 \%$ del total), de los cuales tres cobran cierto protagonismo, aunque la situación migratoria de dos de ellos está regularizada. ${ }^{1}$ Yamal, personaje de origen marroquílibanés, parece socavar los estereotipos nacionales de los inmigrantes árabes: es un pintor económicamente desahogado y dueño de un bar, el único inmigrante de todas las obras analizadas que contrata a nacionales españoles (por lo cual invierte la asimetría económica). Es también el único capaz de un passing (Renfrow, 2004, pp. 491-492), logrando "pasar" por español (gracias a su poder económico y éxito social) y quien presenta lo que podríamos denominar como una sexualidad nonormativa (todos los personajes inmigrantes en las obras analizadas son heterosexuales, lo que se conjuga con los valores tradicionales que generalmente encarnan). No obstante, aquí se acaba la subversión y se da paso a la transcripción de una imagen orientalizada del amante que también remite, según lo que expone Edward Said en Orientalismo, al proceso de la idealización del paria. Yamal es misterioso, irracional y exótico. Es un representante de todo lo opuesto a los fundamentos de la cultura de Occidente, cuyas virtudes son la claridad, la racionalidad y la homogeneidad (Said, 2008, pp. 68-69). Recuerda la imagen del paria filtrada por la tradición occidental. Su caracterización difiere muy poco de la del personaje del jeque del bestseller de Edith Maude Hull, El árabe. Este es un personaje que es capaz de hacer enloquecer a las mujeres occidentales, a pesar de su violento carácter. Esta representación fantasmática y la referencia a la imagen occidentalizada debilita sustancial-

\footnotetext{
${ }^{1}$ Aunque la situación migratoria de ambos personajes está arreglada (tienen la ciudadanía española), la mayoría de los autóctonos los considera como inmigrantes debido a sus "marcas identitarias" (cuerpos, pieles, acentos o cabellos) (Ahmed, 2000).
} 
mente el potencial subversivo de este personaje y, argumentalmente, lo convierte en un simple generador de hilos sensacionales y temas sentimentales. Siendo un híbrido que oscila entre el antihéroe redondo y el héroe plano, su función transgresora viene debilitada por el juego sobre los estereotipos corrientes relativos a los hombres árabes y la motivación biológica (deseo carnal) que en gran medida lo condiciona.

En lo referente a la imagen de los inmigrantes, como indica Gwari Parameswaran (2007), es necesario considerar no solo las diferencias en sus costumbres, valores y lo que Sara Ahmed (2000) denomina como "marcas identitarias" (cuerpos, pieles, acentos o cabellos), sino que también debemos prestar atención a las dinámicas de poder que se entablan entre el grupo dominante y el minoritario. En este contexto, el hilo de Susana, nacida en Alcalá de Henares, pero de padres guineanos, parece sintomático, dado que la chica se ve siempre obligada a demostrar su condición de española cuando intenta conseguir un puesto de trabajo. Ni su español nativo ni sus conocimientos de la realidad peninsular le asegurarán el reconocimiento de su ciudadanía, ya que la primera y más fuerte barrera que encontrará será la de su "marca identitaria", perceptible a primera vista. Por mucho que consiga posicionarse en el rol de sujeto (convence a la dueña de la tienda para que la contrate), alterando y remodelando así su concepto de pertenencia al espacio social, seguirá siendo siempre un personaje condenado a superar las distintas pruebas de las mujeres autóctonas y a sentir su compasión. Es más, consigue salir de una relación abusiva solo gracias a los iluminados sermones de una española privilegiada, social y económicamente (una donante dentro de las aportaciones de Propp). También Amina (personaje femenino y marroquí) logra alzarse gracias a los conocimientos aprehendidos de los autóctonos: la mujer, al fin y al cabo, no se casa con su prometido Karim, toma conciencia de sus derechos y reconoce la posibilidad de forjar independientemente su propio destino gracias a la ayuda de los representantes de la cultura occidental, para quienes se asemeja a la figura de la princesa (Propp) pasiva, a la que tienen que salvar. Ambos casos ilustran la tan condescendiente actitud colonizadora de los occidentales para con los inmigrantes (y para con las mujeres en particular) de la que hoy la mayoría de la población española hace gala y que, además, es sintomática para casi todos los personajes nativos de la Península en las cuatro obras analizadas.

En cuanto a los demás personajes de inmigrantes en Cosmofobia hay que subrayar que todos, con no más de un par de salvedades (p.ej. Amina tiene sexo prematrimonial), han sido en su mayoría retratados según los prejuicios vigentes. Si consideramos a la minoría marroquí, por ejemplo, las mujeres resultan ser religiosas, sumisas y orientadas a satisfacer las necesidades de sus familias (motivación completamente social), mientras que los hombres son machistas, abusadores y muy tradicionales (es menester señalar que aparece un personaje masculino, Aziz, que es la excepción de la regla). A pesar de esta deficiencia, Cosmofobia es una de apenas dos novelas que, al menos parcialmente, presta su voz a los propios inmigrantes sin 
recurrir a la instancia narrativa intermediaria, convirtiendo a ciertos personajes en activos y dinámicos.

En Háblame, musa, de aquel varón de Dulce Chacón el personaje secundario de Aisha, la guardesa del cortijo del español Ulises, también encarna una serie de ideas estereotipadas y prejuiciosas que se tienen hoy día en España sobre las mujeres marroquíes: Aisha es inculta, ingenua y, sobre todo, es representada de manera estetizante, de manera similar a lo que ocurre con Yamal. Aunque el trato entre Aisha y Matilde (una burguesa española a la que Ulises invita a su casa) no es de carácter condescendiente, el personaje del inmigrante adquiere rasgos de una figura que desempeña la doble función de contrapunto: narrativo (caracterización indirecta de Matilde) e ideológico (contraste sociocultural). Según el estereotipo de los parias en la literatura, la narradora idealiza la posición de Aisha, haciéndolo sobre todo de su marginalidad, exterioridad y su supuesta unión con la naturaleza, convirtiéndola así en una suerte de "buen salvaje", cuya actitud honesta e ingenua en conjunto con su analfabetismo contrasta con la decadencia del ambiente burgués español. Es también el personaje de Aisha, la auxiliar (Propp) de Matilde, quien introduce un tema tan recurrente en la literatura de la inmigración como puede ser el relato de viajes traumáticos. En este caso, se describen los ataques de pánico que la mujer marroquí sufre. La retrospección onírica sobre la boda de Aisha con su primer esposo en Marruecos ofrece un desfile de detalles folclóricos con un "especial énfasis en los colores, sabores, olores y cánticos; proponiendo, en suma, un mundo de sensualidad que se ajusta muy bien a uno de los estereotipos orientalistas más arraigados" (Cruz, 2005, p. 150). Como observan Jacqueline Cruz y Mary Nash, la atención prestada a los aspectos más superficiales de la cultura marroquí crea un ambiente exótico alrededor de Aisha y este exotismo se inscribe dentro del marco del "proceso de homogeneización cultural y religiosa de la población inmigrante [es decir], otro mecanismo de alteridad esquematizadora" (Nash, 2005, p. 150). A los estereotipos culturales y religiosos existentes deberíamos también añadir aquellos económicos y sociales, dado el bajo nivel adquisitivo de Aisha y su condición de sirvienta. Y una vez más nos las tenemos que ver con un personaje plano, pasivo y de motivación social.

La muy reconocida por la crítica En la orilla de Rafael Chirbes, considerada la novela de la crisis por antonomasia, presenta al personaje marroquí de Ahmed como una suerte de "otro entre los otros", un antihéroe (Propp) tanto para la comunidad autóctona como para la suya propia. Ahmed se rebela contra sus compatriotas, quienes subrayan su otredad, a través de su religión y su oposición hacia la decadencia del mundo occidental. Consciente de que las tensiones entre los autóctonos y los inmigrantes se arreciaron a causa de la crisis económica, Ahmed opta por no agudizarlas, tratando de invisibilizarse de cierta manera. Aunque la representación del inmigrante persigue demostrar que el potencial del extranjero no se limita al campo laboral, poniendo de manifiesto las capacidades intelectuales y las ricas experiencias culturales de Ahmed, su retrato sigue estando anclado al modelo estereotipado del 
paria de manera sustancial: trabajador pobre, desempleado, una carga económica para el Estado y que, en cierto grado, está consumido por la ansiedad producida por el rechazo social. A pesar de que su condición de explotado parece estar vinculada a su pobreza (y no tanto con que sea musulmán), la figura del paria extremo, explotado por el sistema capitalista, sirve para recalcar los devastadores efectos de la crisis. Equivale a la figura de la princesa (Propp), pasiva en gran medida. El personaje inmigrante que constituye su contrapunto, Abdeljaq (agresor dentro de la tipología del formalista ruso), potencia la acumulación de binomios de la prosa de la inmigración porque este personaje encarna los miedos de los autóctonos relativos al terrorismo, al fanatismo, a la competitividad en el mercado laboral y el ansia de venganza.

Al prestarle la voz a Esteban, un narrador algo ignorante y lleno de prejuicios, existe un intento de reprobar y ridiculizar las actitudes xenófobas y racistas. No obstante, no se consigue ni desmantelar los estereotipos sobre los inmigrantes ni las típicas posturas hacia ellos. En su mayoría, siguen siendo representados como personajes tipo, carentes de psicología individual, motivados solo social y étnicamente, como perturbadores del orden público (son ladrones, prostitutas, traficantes y terroristas potenciales), como una amenaza latente para los patrones culturales occidentales (dada su irracionalidad religiosa que la desesperación económica agrava) y agresores. En este contexto cabe señalar que Esteban se refiere de forma peyorativa a los espacios en los que los inmigrantes desarrollan su actividad laboral, como son las carnicerías halal, las "tiendas chinas" de productos baratos o las cunetas de las carreteras, que remiten respectivamente y de manera más o menos obvia y manida a las categorías de lo nauseabundo, de la rivalidad económica y de la prostitución. El desdén hacia estos espacios, junto con la metáfora del pantano inmovilizador y paralizador contrapuesto al espacio urbano (contraste que remite a la crisis económica que estalló en 2008), parece servir de herramienta para subrayar la segregación social que se vive en la España de hoy en día.

En Ventajas de viajar en tren de Antonio Orejudo (y aquí sintetizaré, obviando su dimensión metaficcional y cervantina ${ }^{2}$ ) existe un relato sobre algunos casos psiquiátricos, entre los cuales aparece la historia del personaje de $\mathrm{Makeli}^{3}$, un inmigrante de Tanzania que padece de acatisia, un trastorno que no solo le impide mantenerse quieto, sino que también le obliga a tener que cambiar de lugar. Su enfermedad mental podría ser entendida como una metáfora de la movilidad de los

\footnotetext{
${ }^{2}$ Es necesario subrayar que Ventajas de viajar en tren es la única de las novelas analizadas que no se inscribe en el código realista, ya que se trata de un texto fuertemente metaliterario e intertextual que opera dentro del marco de lo grotesco.

${ }^{3}$ El nombre del personaje es inexacto, de acuerdo a sus propias palabras: "Yo, aunque tengo problemas con la comida, tengo más problemas con la identidad, porque en unos papeles me llamo Makeli Gasana Anastase, que significa «Anastasio, me cago en tu puta madre»; en otros, Migueli Casona Nastase, y en otros Macarra del Casino Anacleto, según sea el guardia que los haya hecho [...]" (Orejudo, 2011, p. 117).
} 
inmigrantes, quienes se ven obligados a abandonar su país de origen. El mismo diagnóstico revela la dimensión metafórica de su plasmación: "El paciente presenta agitación psicomotriz, exceso de actividad motora poco productiva. Ansiedad y tensión interior, sudoración, falta de higiene personal, malnutrición, delirios de identidad, faltas de ortografía" (Orejudo, 2011, p. 117). El breve resumen de su trastorno presenta el vínculo existente entre su enfermedad mental y una serie de ideas preconcebidas sobre los inmigrantes, ya que el enfermo es alguien inseguro, sucio, hambriento, culturalmente heterogéneo e inculto. Así, a modo de burla, el narrador vincula este personaje con los temas típicos de la literatura paria: impureza, corrupción, podredumbre, contaminación y raza vil. Su propia condición mental refiere al estereotipo del inmigrante irracional e inadaptado a la tradición de la razón ilustrada occidental. $\mathrm{Su}$ historia, una suerte de cuento de tránsito colmado de experiencias extremas y traumáticas (Makeli sobrevivió a la exterminación de sus compañeros en su escuela, tuvo que transitar África para conseguir refugio, vivió en las deplorables condiciones del campo de refugiados, transitó en patera hacia España, etc.), es sintomática de un sinnúmero de huidas de conflictos bélicos en los países de origen de los refugiados ${ }^{4}$. Además, la misma narración, compuesta de una sola frase que engloba un sinfín de episodios de su vida de refugiado e inmigrante, refleja el ritmo frenético de las experiencias de Makeli que van en consonancia con su enfermedad.

El abuso laboral extremo que Makeli sufrió en España (trabajó en un invernadero donde se usaba pesticida letal para seres humanos, se alimentaba a los trabajadores con verdura pútrida, se les permitía ducharse solo en las instalaciones de riego y se les castigaba con palizas) remite claramente al imaginario de la esclavitud. Los inmigrantes están representados como entes deshumanizados, objetos sin voluntad ni poder y víctimas del capitalismo imperialista y explotador. Es también de interés que lo vulgar (que los graves errores ortográficos y gramaticales de Makeli reflejan), asociado generalmente al dialecto andaluz (y al gaditano en particular), en la novela recibe una transcripción fonética ("soldao", "guiao", "tol camino", "nel campo", etc.). Este hecho parece vincular la otredad lingüística endémica con la inmigrante, es decir, se teje una equivalencia entre el Otro interior y el exterior. Dado que el propietario de la granja equivaldría a la figura del falso donante (el empleador resulta ser un agresor en realidad, "ofreciendo" condiciones laborales infrahumanas), el inmigrante podría equipararse a la figura del héroe que se opone a las injusticias sociales. No obstante, debido a sus carencias (económicas, intelectuales y hasta lingüísticas) no podremos considerarlo como tal, sino más bien, de nuevo, como la figura de una princesa (Propp) en apuros.

\footnotetext{
${ }^{4}$ Otro personaje de inmigrante que representa esta clase de historias de tránsito es Ismael de Cosmofobia de Etxebarria, un chico joven de Costa de Marfil que realizó el tránsito desde la África Subsahariana hasta la España.
} 
Llegados a este punto, me gustaría presentar algunas conclusiones generales que no solo concuerdan con otros estudios recientes sobre la imagen de los inmigrantes en la narrativa española, sino que también me gustaría que mi aportación inspirara estudios futuros que puedan profundizar sobre un tema de tanto interés humano. Hemos visto que los discursos primordiales en la construcción de la Otredad en cuanto valor negativo son el discurso legal (inmigrantes como amenaza para el orden público), el económico (carga físcal para el Estado, competencia laboral), el discurso, digamos, de la modernidad (amenaza para valores occidentales tales como son la racionalidad, la formación, el progreso, la autosuperación, etc.) $\mathrm{y}$, de manera mucho menos acentuada, el médico (con los inmigrantes entendidos como amenaza biológica y biopolítica). A ello deberíamos añadir una corriente "inmigrantófila" que oscila alrededor de las actitudes paternalistas y fantasmáticas (p.ej. orientalistas), típicas de las figuras de donantes y auxiliares (Propp). De igual forma, también es de notar que la codificación de los inmigrantes en todas las obras analizadas no difiere muchoni de los estereotipos ni de los prejuicios que corrientemente encontramos en España. En muchas ocasiones se limita a una imagen dicotómica, que oscila entre dos polos: el de la víctima merecedora de compasión y el del abusador que debe ser castigado (la figura de la princesa frente al agresor, en términos de Propp). En este sentido, estos personajes inducen emociones que los narradores han prefabricado y que, a su vez, refuerzan lo binario y una visión sumamente maniqueísta de Occidente frente al resto del mundo. Para reforzar esta dicotomía y conseguir un fuerte contraste entre lo propio y lo ajeno, los narradores minimizan (en muchas ocasiones) la motivación psicológica de los personajes de inmigrantes y los condicionan según su clase social, etnia y/o estatus político. De este modo, muy pocas veces surgen personajes redondos, con motivaciones heterogéneas, que pudieran alejarse de los personajes que subvirtieran la asociación con la categoría de parias. El binarismo occidental para con los inmigrantes o su descendencia (aunque no solo) también se ve intensificado el hecho de que en ninguna de las novelas aparecen hijos de parejas mixtas, lo que nos lleva a preguntarnos si el prejuicio colonizador contra el mestizaje sigue vigente. Aún cuando los personajes de inmigrantes no vienen representados de manera negativa, también encontramos otras huellas notables de la actitud colonizadora (o de donantes y auxiliares) cuando a estos se les sigue relacionando con el campo semántico de la deficiencia paria: de recursos, de derechos, de formación y de satisfacción (siendo la única excepción el personaje de Yamal de Cosmofobia). Resulta que la promesa de la felicidad y del bienestar económico, principales causas motoras de la emigración, paradójicamente conducen a la decepción, al desencanto y al en todos los sentidos, de manera que la desesperación de estos personajes (y las acciones que emprenden por ella) en muchos casos es el principal motor de la trama que dista mucho del final feliz de los cuentos maravillosos, que se basan (como las novelas comentadas) en tan fuertes dicotomías. 
Con frecuencia, los personajes de inmigrantes desarrollan el papel de alumnos o acólitos de los autóctonos, especialmente los personajes femeninos. Ellas son instruidas por las mujeres occidentales y así se inscriben en hilos argumentales que destacan una mejora gracias a las enseñanzas de españolas iluminadas (Cosmofobia ofrece la mayoría de ejemplos al respecto), como si se tratara de un makeover mental, un reto o un acto de misericordia cristiana. En este sentido, se confirma la tesis de Chandra Talpade Mohanty sobre los "ojos occidentales condescendientes", con los que las feministas de países desarrollados perciben a las mujeres de países en vías de desarrollo (como retrogradas, ignorantes, religiosas, tradicionales y, sobre todo, por salvar), hecho que remite directamente a la llamada "colonización discursiva" de la que habla Mohanty (2003) y Maryanne L. Leone (2013). Comentando la novela de Etxebarria, la segunda investigadora incide además en el afán de Etxebarria en homogenizar las experiencias femeninas independientemente de su etnia, estatus económico, edad y otras señas de identidad, hecho que refuerza la visión paternalista que muchos españoles y otros tantos occidentales (2013), comparten.

En Háblame, musa de aquel varón el personaje inmigrante sirve de contrapunto al personaje autóctono: la locuacidad sin tapujos de Aisha pone en relieve el silenciamiento de Matilde. Casi todas las obras denuncian la explotación laboral de los inmigrantes, de modo que podemos deducir que esta clase de personajes pretende servir de herramienta plástica y sugerente a la denuncia al sistema capitalista por ser ellos precisamente quienes adquieren el valor instrumental para el capital, como mera mano de obra en los empleos más "viles" y "contaminantes". Además, en varias ocasiones se hace una alusión más clara que menos al imaginario de la esclavitud (principalmente abusos laborales cometidos por los autóctonos, como presenta la historia de Makeli).

Sorprende que la mayoría de las obras analizadas no intenten socavar los fundamentos de los discursos de exclusión (legal, económico, médico, de modernidad, etc.) con lo que sería la herramienta de lucha más eficaz dentro del texto literario: el uso del propio discurso. En otras palabras, los narradores de las novelas en cuestión no operan al mismo nivel que el instrumento de opresión (discursivo), y no consiguen socavarlo como bien podrían hacer, a partir de, por ejemplo, deformaciones lingüísticas burlonas o reapropiaciones del lenguaje racista, desmantelando sus fundamentos desde dentro. Los narradores optan, en cambio, por estrategias más directas. Así es que a través de la plasmación de las tramas, de un modo más o menos explícito o (menos frecuentemente) implícito, condenan las injusticias a costa de la reproducción de estereotipos estereotipos.

Ventajas de viajar en tren de Orejudo constituye la excepción, ya que intenta subvertir estos estereotipos en vez de representarlos o realizar un diagnóstico de lo fácilmente perceptible a través de la inversión de la norma, al nivel discursivo. Como se ha mencionado ya antes, es el único texto que no se inscribe en el código realista. En el seno de la narración de la novela se ridiculiza lingüísticamente la 
"norma racial blanca" gracias a que el protagonista usa repetidamente la colocación "entidad blanca" como sinónimo del equipo de fútbol del "Real Madrid" (Makeli sueña con ser jugador en este club). Así, surgen comentarios bien ambivalentes e interpretables fuera de lo literal, como cuando Makeli admite lo siguiente: "[tengo] puestas mis esperanzas en la entidad blanca, haciendo palomitas tol santo día con un balón que yo me imagino, a ver si el míster se fija en mí” (p. 129). Además, en ocasiones el lenguaje de Makeli se acerca de manera grotesca y burlona al registro formal de lo normativo y, por extensión, al discurso legal, como ocurre en este ejemplo:

[conseguí] llegar a una playa de la provincia de Almería, cuya tierra y pesticidas guardo en mi corazón por ser allí donde trabajé por primera vez gracias al buen oficio de un modesto horticultor que se arriesgó a ser sancionao por la normativa comunitaria a causa de permitirnos el recoger de su invernadero los tomates, siempre y cuando fuera sin parar, a no ser por el desmayo o muerte que proporcionaban sus pesticidas caseros que engordaban el tomate como Dios y desinflaban el corazón de los veinticinco negros, luego veinticuatro, luego veintitrés y luego veinte. (Orejudo, 2015, p. 124)

La yuxtaposición del registro formal de la normativa y las formas arcaicas con el contenido macabro del enunciado y las particularidades del dialecto andaluz crea un discurso híbrido, heterodoxo, denunciador y, sobre todo, fuertemente sugestivo. Además, la descripción del explotador ("un modesto horticultor [que] se arriesgó [y nos permitió trabajar] sin parar"), supuestamente integrado por un Makeli narrador, expone al mismo como un falso donante, un hipócrita, racista y, en consonancia con las pautas de subversión y reapropiación discursiva de Orejudo, como un "negrero".

Aun visto esto, tanto la obra de Orejudo como las demás, en lugar de deconstruir los estereotipos, cuestionar sus fundamentos y así demolerlos, lamentablemente los acentúa y explota para alcanzar fines narrativos dramáticos o para recalcar ciertos posicionamientos ideológicos. El personaje de Makeli reproduce la imagen de los africanos codificada en la cultura occidental: es un buen salvaje a quien se puede engañar, del cual es fácil aprovecharse. África sigue siendo la fuente de recursos que Europa explota, ya que, por desgracia, sigue ofreciendo "recursos humanos" para las sociedades occidentales. Zygmunt Bauman ofrece un comentario relevante en lo referente a esta cuestión: "los inmigrantes, y sobre todo los recién llegados, exhalan ese leve olor a vertedero de basuras que, con sus muchos disfraces, ronda las noches de las víctimas potenciales de la creciente vulnerabilidad" (2005, p. 78). No obstante, a pesar de que los personajes de inmigrantes y descendientes de inmigrantes sean tratados con condescendencia y prejuicios, en varias ocasiones, en las novelas analizadas van apareciendo salvedades: en cierto modo el personaje de Aziz, quien disfruta del éxito y es apreciado por la comunidad en Cosmofobia; la relación afable entre Aisha y Matilde en Háblame, musa, de aquel varón; algún rasgo caracterizador 
de Amhed -culto e inteligente- en En la orilla y el hecho de que el estereotipo de inmigrante desarraigado de Makeli de Ventajas de viajar en tren está en clave de burla y debe leerse dentro del código no realista de esa novela. Es comprensible que los narradores que representan a los desfavorecidos se valgan de la función de espejo de su tiempo que ofrece el género de la novela realista y que en consecuencia, reproduzcan el contexto socio-histórico retratando la precariedad social en torno a la inmigración de manera verosímil. A pesar de ello, y aunque podamos comprender las intenciones de los escritores a la hora de denunciar las injusticias de los personajes inmigrantes, también puede ser verdad que tal plasmación, que oscila alrededor de la victimización y que normaliza la situación desfavorecida de estas personas, corre el riesgo de convertirse en un peligro más que en ayuda. Es muy posible que la divulgación de este tipo de percepciones vaya en detrimento de la comunidad inmigrante, o la de cualquier otra, por reducir la pluralidad de la realidad a conceptos identitarios estereotipados y homogeneizadores. 


\section{BIBLIOGRAFÍA}

Ahmed, S. (2000). Strange Encounters: Embodied Others in Post-Coloniality. Nueva York: Routledge.

Álvarez Blanco, P. (2011). De etnomanías y otros terrores: literatura e inmigración en la España del siglo XXI. En P. Álvarez-Blanco, y T. Dorca (eds.), Contornos de la narrativa española actual (2000-2009). Un diálogo entre creadores y críticos (55-65). Madrid-Frankfurt: Iberoamericana.

Bauman, Z. (2005). Vidas desperdiciadas. La modernidad y sus parias. Barcelona: Paidós.

Chacón, D. (2005). Háblame, musa, de aquel varón. Barcelona: Planeta.

Chirbes, R. (2013). En la orilla. Barcelona: Anagrama.

Clifford, E., y Kalyanpur, M. (2011). Immigrant Narratives: Power, Difference, and Representation in Young-Adult Novels with Immigrant Protagonists. International Journal of Multicultural Education, 13 (1), 1-20.

Cruz, J. (2009). Entre la denuncia y el exotismo: la inmigración marroquí en Háblame, musa, de aquel varón. En A. Encinar, y C. Valcárcel (eds.), Escritoras y compromiso: literatura española e hispanoamericana de los siglos XX y XXI (397-414). Madrid: Visor Libros.

Ducrot, O., y Todorov, T. (1974). Diccionario enciclopédico de las ciencias del lenguaje. Buenos Aires: Siglo Veintiuno Editores.

Etxebarria, L. (2007). Cosmofobia. Barcelona: Destino.

Galán, E. (2006). La representación de los inmigrantes en la ficción televisiva en España. Propuesta para un análisis de contenido. El Comisario y Hospital Central. Revista Latina de Comunicación Social, 61. Recuperado de http://www.ull.es/publicaciones/latina/200608galan.htm.

Leone, M.L. (2013). Narrating Immigration, Gendered Spaces, and Transnational Feminism in Lucía Etxebarria's Cosmofobia (2007). Letras Hispanas, 9.1, 47-63.

Morales, J.F., y Moya, M.C. (1996). Tratado de Psicología Social. Procesos básicos (vol. 1). Madrid: Síntesis Psicología.

Moya, M., y Puertas, S. (2008). Estereotipos, inmigración y trabajo. Papeles del Psicólogo, 29 (1), 6-15.

Nash, M. (2005). Inmigrantes en nuestro espejo: Inmigración y discurso periodístico en la prensa española. Barcelona: Icaria.

Navarro, E. (2009). La ciudad feliz. Barcelona: Random House.

Odartey-Wellington, D. (2012). El imaginario de la inmigración en la narrativa española contemporánea. En L. Silvestri, L. Frattale, y M. Lafèvre (eds.), Rumbos del hispanismo en el umbral del Cincuentenario de la AIH (461-468). Roma: Bogatto Libri.

Orejudo, A. (2015). Ventajas de viajar en tren. Barcelona: Tusquets.

Parameswaran, G. (2007). Enhancing Diversity Education. Multicultural Education, 14 (3), 51-55.

Propp, V. (1971). Morfología del cuento. Madrid: Fundamentos.

Renfrow, D.G. (2004). A Cartography of Passing in Everyday Life. Symbolic Interaction, 27 (4), 485-506.

Said, E.W. (2008). Orientalismo. Barcelona: Debolsillo.

Sławiński, J. (2002). Motywacja. En J. Sławiński et al. (eds.), Słownik terminów literackich. Wrocław: Ossolineum.

Talpade Mohanty, C. (2003). Feminism Without Borders: Decolonizing Theory, Practicing Solidarity. Londres: Duke University Press.

Zavko, M. (2009). La imagen del inmigrante en la novela española actual. Saggi /Ensayos/ Essais/Essays, 2, 163-172. 